\title{
Brokerage Of Human Expertise: An Overview Of The Expert Websites On The Internet
}

\author{
Dr. Vipul K. Gupta, (E-mail: gupta@sju.edu), Saint Joseph's University \\ Dr. Myrna Murtaza, (E-mail: mmurtaza@mtsu.edu), Middle Tennessee State University \\ Dr. H.V. Ramakrishna, (E-mail: hxr7@psu.edu), Penn State Great Valley
}

\begin{abstract}
Expert web sites, an online resource, provide a useful connection between knowledge seekers (i.e., the consumers of knowledge) and knowledge providers (i.e., experts). Since 1998 there has been a proliferation of expert web sites. As the phenomenon of expert web sites is still relatively new, there is very little research on the effectiveness of these services. Thus it is difficult for consumers of this type of service to make informed choices. This paper is an attempt to provide a general overview of the effectiveness of expert web sites. We have presented a brief synthesis of the features of the most popular expert web sites along with a conceptual framework that clearly identifies the issues that must be examined in evaluating the effectiveness of the sites. The framework is meant to generate some empirical research regarding the new phenomenon and the results of this empirical research could then assist consumers in making informed decisions regarding their choice of expert web sites to suit their needs.
\end{abstract}

\section{Introduction}

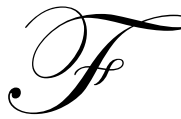

rom its early use as a communications resource, the Internet has developed into a vast information resource. The dramatic growth in digital content and user bases has been consistent over the past ten years, outstripping projections and increasing the value of the Internet as a widely used source for information search and retrieval -- Jupiter Media Metrix reports that internet usage increased among all age groups in the US during April 2001, overall web usage grew 19\% from April 2000, and the greatest percentage gain came in the 55 years-and-over demographic group, which was up $33 \%$ for the year, while the number of 18 - to 24 -year olds online was up 32\% [4]. However, finding specific information on the ever-expanding Internet has always been a challenge. Most users rely on search engines for navigating through sites to find desired information. These search engines, like Yahoo, InfoSeek and Lycos, use Boolean search methods and/or search robots to help users find appropriate websites that contain the searched information. There remain two shortcomings to this method. First, even though the websites meet the search criteria, they often do not contain the right information. Second, searches often match a great number of websites and the user has to comb through them to find the most appropriate site, then find the right information within that site.

Until few years ago, the only alternative method of seeking out the answer to a specific question was the Internet newsgroup [5]. Newsgroups are thousands of communities of common interest where questions and answers could be posted about a particular topic. At the peak of their popularity, when online courtesy was rarely violated, responses tended to be thoughtful, accurate and trustworthy. Unfortunately, the present structure of the newsgroups is plagued with several shortcomings:

Readers with comments or questions are encouraged to contact the authors via email. 
- The information required by a user may be buried inside the threaded discussion and not readily available,

- When an interested user posts a question eliciting single or multiple responses, there is no way to guarantee the accuracy of those responses, and

- $\quad$ Since Newsgroups are an asynchronous form of collaboration, they do not support instant decision-making. This is because the subject matter expert(s) may not read the question/posting immediately.

As E-commerce blossomed in late 1990s, entrepreneurs took notice and attempted to improve upon the search engine concept. A site named ask.com was born. This site allows people to enter a question in plain English. The site then utilizes natural language query to recommend a series of websites that might contain the answer. However, the task of determining the specific site that may contain the right information was still up to the user.

Next came a site called About.com, which was one of the first sites to use human experts [1]. These experts kept track of the best, most appropriate websites that fell within their specific area of expertise. The wedding expert could intelligently discuss the sites that allow brides to search for churches and reception locations. The college basketball expert knew the best site for a printable NCAA tournament bracket. The human interaction was a welcome change to the cold, unfeeling information that was spit out by automated search engines, but users still were on their own when it came to finding that specific nugget of information on any of the recommended sites.

While the idea behind about.com had merit, there were still those who were frustrated with reading page after page of information. About.com sparked the idea of "expert websites." These sites would give average people access to experts in all types of topics. The experts would then answer and enlighten those with questions, without having to search through pages of information on a static website. Unlike user groups, the experts have a commitment to answer all questions, rather than having the option of leaving the question unanswered.

The thrust of this paper is on discussing some of the popular "expert websites" and presenting our conceptual framework for evaluating the effectiveness of these services. The rest of this paper is structured as follows: first, background information on expert sites is provided. Secondly, business models engaged by various expert sites are discussed, followed by issues and concerns on the use of these sites. Next, we discuss the venture capital investment activity in this space, followed by the conclusions and managerial implications.

\section{Background On Expert Sites}

An expert web site is an online resource, which provides knowledge seekers with the ability to submit requests for information to a topical expert [14]. Therefore, in its simplest terms, an expert site is a question and answer site. We have identified 14 sites that could be considered as expert sites, though some are more "expert" than others. Basically, expert sites provide inquisitive users with a panel of one or more experts on a particular topic or category, for example, business, personal interests, and technology. The user asks, the expert answers. It's as simple as that.

Each site takes the basic question and answer idea and gives it a different twist. Many claim to be the first, biggest, fastest growing or best, but the truth is that these sites are too new to make any substantial claims. Changes are taking place every day, with new sites appearing and existing ones being bought. In late 1999, the New York Times bought Abuzz.com [11], and About.com purchased XpertSite and renamed it to AskMe.com. Table 1 includes a quick overview of the current expert sites, when they started and their business models. 
Table 1 Overview Of Expert Sites

\begin{tabular}{|c|c|c|c|c|}
\hline Site & Launch & Cost/Business Model & No. Of Experts & Advertising? \\
\hline Abuzz.com & Jan. 19, 2000 & $\begin{array}{l}\text { Free. User posts question to site } \\
\text { and anyone can answer. }\end{array}$ & 5000 & Yes \\
\hline $\begin{array}{l}\text { AskMe.com } \\
\text { (formerly Xpertsite.com) }\end{array}$ & $\begin{array}{l}\text { October } 1999 \\
\text { (beta) } \\
\text { February } 2000 \\
\text { (final) }\end{array}$ & $\begin{array}{l}\text { Free. User posts question and any- } \\
\text { one can answer. Questioners will } \\
\text { eventually pay for answers; site } \\
\text { will keep a percentage of the } \\
\text { transaction. }\end{array}$ & 30,000 & No \\
\hline Exp.com & $\begin{array}{l}\text { September } \\
1999\end{array}$ & $\begin{array}{l}\text { User chooses from a pool of ex- } \\
\text { perts, who negotiate a fixed or } \\
\text { hourly fee; site takes } 20 \% \text {. Aver- } \\
\text { age is } \$ 40-50 \text { per answer. }\end{array}$ & 20,000 & No \\
\hline ExpertCentral.com & October 1999 & $\begin{array}{l}\text { Most are free. User chooses from } \\
\text { a pool of experts who negotiate a } \\
\text { price if charging; site takes } 15 \% \text {. } \\
\text { Average is } \$ 25\end{array}$ & 5,600 & Yes \\
\hline InfoRocket.com & $\begin{array}{l}\text { December } \\
1999\end{array}$ & $\begin{array}{l}\text { User asks a question and states } \\
\text { price he is willing to pay, as well } \\
\text { as other criteria. Anyone can } \\
\text { make a bid to answer it for that } \\
\text { price, higher or lower. Site takes } \\
20 \text { percent. }\end{array}$ & Over 10,000 & Yes \\
\hline Keen.com & $\begin{array}{l}\text { November } \\
1999\end{array}$ & $\begin{array}{l}\text { User chooses expert. Site sets up } \\
\text { phone call and handles billing, tak- } \\
\text { ing } 30 \% \text {. Avg. price per minute is } \\
77 \text { cents. Some answers are free. }\end{array}$ & 40,000 & No \\
\hline AskAnExpert.com & Not available & $\begin{array}{l}\text { Targeting school-aged children, } \\
\text { site is sponsored by Pitsco and } \\
\text { Lego }\end{array}$ & Not available & No \\
\hline Experts Exchange.com & 1996 & $\begin{array}{l}\text { Eighty computer technology cate- } \\
\text { gories; users earn "knowledge cre- } \\
\text { dits" by completing surveys and } \\
\text { viewing ads. }\end{array}$ & 45,000 & Yes \\
\hline $\begin{array}{l}\text { Experts.com } \\
\text { (not really an expert site - } \\
\text { more of a directory) }\end{array}$ & 1997 & $\begin{array}{l}\text { Yellow Pages for finding experts; } \\
\text { uses a directory model in which } \\
\text { experts pay to have their services } \\
\text { listed. }\end{array}$ & Not available & Yes \\
\hline Frenzi.com & Spring, 1999 & $\begin{array}{l}\text { Uses barter-based credit system in } \\
\text { lieu of fees. }\end{array}$ & Not available & No \\
\hline GoofyGuys.com & Not available & $\begin{array}{l}\text { Free service that currently focuses } \\
\text { on computer questions but plans to } \\
\text { expand into general topics. }\end{array}$ & Not available & Yes \\
\hline Expert City.com & Dec. 1999 & $\begin{array}{l}\text { Provides technical computer ad- } \\
\text { vice to consumers. Flat } \$ 10 \text { fee } \\
\text { that connects users with experts } \\
\text { via live chat and shared web ses- } \\
\text { sions. }\end{array}$ & 150 & No \\
\hline KnowPost.com & April, 1999 & Point System \& advertising & 10,000 & Yes \\
\hline AllExperts.com & July, 1998 & $\begin{array}{l}\text { Advertising \& newsletter subscrip- } \\
\text { tion that can be sold - part of fly } \\
\text { cast network }\end{array}$ & 10,000 & Yes \\
\hline
\end{tabular}

\section{Business Models Of Expert Web Sites}

There are several different business models by which the expert sites operate, and a discussion on each type follows. 
The first is an auction/negotiation strategy where sites take a percentage of the fees earned by experts. Sites that operate this way include ExpertCentral.com, InfoRocket.com, and ExpertCity.com. The positive aspects of the auction/negotiation strategy is that users can pay what they want for answers, and since the experts are being paid, the user can be fairly certain that the information provided will be high quality. On the negative side, users cannot be sure that the answers they get are good answers until after they have paid for them. Additionally, most answers can e found free elsewhere on the Internet if the user takes the time to search for it.

The second model is an exchange model where users accumulate points or credits by answering a question and spends the points/credits by asking a question. Sites that fall in this category are KnowPost.com, ExpertsExchange.com, and Frenzi.com. Most of these sites are financed through advertising dollars or contractual agreements with other sites. The best part about this model is that there is no monetary cost involved. However, many users will often give lazy answers to questions in order to build up their own points.

The third model is a truly free model where people can obtain information for no cost at all. These sites include Abuzz.com, AllExperts.com, and GoofyGuys.com. Advertising pays for most truly free sites, although AskAnExpert.com, an educational site aimed at children, is fully sponsored by companies such as Pitsco and Lego. What people like most about these sites is that they are friendly, conversational and entertaining at no cost to the user. A disadvantage to totally free sites is that the user often must sort through lots of dim-witted answers before they find any good ones.

The fourth model charges some type of flat fee or rate for answers. Keen.com, which has been in the answer business for many years, began its website in November, 1999 [13]. Keen gets the user in touch with the expert and then charges for use of its 900 - or 976- telephone number. The charge is by the minute; the expert receives $70 \%$ of the billings and Keen takes 30\%. Another site that uses this model is ExpertCity.com, a site that provides computer expertise to non-technical consumers. ExpertCity uses technology to allow users and experts to chat live and share web sessions [3]. It charges a flat connection fee of $\$ 10$ and a per-minute session fee. The pros and cons of this model are similar to those of the auction/negotiation model: paid experts usually provide better information, but the users do not know what they are paying for until they receive the answers. Additionally, users do not usually know how much their answer will cost in advance because it depends on the duration of their session with the expert.

Finally, some sites combine elements of each business model. EXP.com, for example, offers some free answers but users must negotiate a fixed price or an hourly rate for more complex queries. AskMe.com (previously XpertSite.com) is currently free, supported by advertising, but plans to institute fees in the near future. Utilizing a combination of business models keeps the expert site flexible and easily adaptable to change.

\section{Issues And Concerns Regarding Expert Sites}

There are several issues to be aware of when searching for and using an expert web site. First, the impartiality of experts and expert web sites can be questionable. Sites such as Xpertsite.com and Exp.com already charge a commission for their expert's services. However, some sites are considering establishing deals with vendors that would result in a payment from a vendor to the site each time an expert refers a specific product or service to a customer and the customer purchases the referred product or service [6]. Such a practice would immediately put a cloud of doubt on the objectivity of these sites.

Secondly, the credibility of the experts dispensing information can be questionable. Who is to say what an expert is? There are two general schools of thought about what makes an expert. Some sites feel that everyone is an expert in some area. Others feel that experts must have extensive education, experience and credentials before they can provide answers [7]. While some sites fall at the extreme ends of this continuum, many are in the middle.

Those sites that feel that experts are an elite group of professionals require rigorous screening processes for their experts. They believe that the integrity of their sites is dependent on the answers given by their experts and the only way to protect that integrity is by being discriminating and selective about the experts on their sites. Users of 
these sites generally receive professional, reliable answers, but for a fee. Sites that fall in this category include AskAnExpert.com, AskMe.com, Keen.com, and ExpertCity.com

Those sites that feel that anyone is an expert in some type of field tend to provide free information, or information at an auction. They promote the free flow of information, rather than the quality of information. The problem with this philosophy is that users do not know who to trust or how good their answer will be. This is an issue, particularly when the site requires payment for the answer. Sites that fall in this category include Abuzz.com, InfoRocket.com, and Frenzi.com.

Both types of sites include some safeguards to prevent the potential problems that arise with "expert" experts and "not-so-expert" experts. The primary safeguard is rating experts and their answers so that any given expert's overall rating can be viewed by anyone who wishes to ask a future question. Some sites that charge for answers even offer guarantees for unsatisfactory answers. Most, however, only use the rating system which is a good way to rate the expert over time, but a user still run the risk of getting an incorrect answer from a usually good expert, or getting a new expert that does not yet have a rating.

Table 2 given below illustrates the issue of the credibility of the experts. The example summarizes several answers that a writer for the New York Times received for the same question on different sites [5].

Table 2 Summary Of Responses From Four Expert Sites On The Same Question

\begin{tabular}{|l|l|}
\hline \multicolumn{2}{|c|}{ The question: If I make scrambled eggs in an old Teflon pan and some of the Teflon flakes off in my eggs, } \\
should I be worried about it?
\end{tabular}

This example demonstrates that the answers range from technical and informative to entertaining. The question of whether or not experts should be pre-screened by the site or if they should be an "average Joe" volunteer is a matter of personal preference. Some like the witty, entertaining answers while some people find this type of advice annoying.

\section{Investments And Venture Capital In Expert Sites}

Regardless of which expert philosophy or business model proves to be dominant in the future, expert sites are here to stay. The larger sites have had no trouble finding investors and larger companies are already buying up many sites. EXP.com has raised \$30 million in venture capital backing from several investors [11]. Go2Net Inc. has invested \$10 million in AskMe.com [10]. The New York Times bought Abuzz.com in January 2000 and wellestablished About.com has bought ExpertCentral.com [10].

The Merger of About.com and ExpertCentral appears to be most significant at this time. These two sites plan to develop partnerships with other sites that include lucrative licensing agreements. This would enable other consumer sites to have a question and answer section by using ExpertCentral.com's technology. AskMe.com is also moving in this direction and is currently negotiating a contract with HomeDepot.com [10]. EXP.com is also cur- 
rently developing profit sharing agreements with sites like Ancestry.com, eHow.com and Astrology.net [1]. This appears to be the direction in which the expert sites are heading.

Keen.com, which has raised a total of $\$ 67$ million in funding, has the biggest amount of venture backing in the advice/expert site arena. Its investors include Microsoft Corporation's co-founder Paul Allen's Vulcan Ventures, Integral Partners, Benchmark Capital, eBay and many others [10]. It plans to make money by taking a 30 percent slice of the transaction between the customer and the "Keen speaker." Overall, most of these sites are currently monitoring their "acquirability" to larger companies. With the backing of larger companies, these acquired sites will have the power to eliminate smaller ones and develop the partnerships that will be integral to their profitability and success.

\section{Managerial Implications And Conclusions}

The potential for information overload entails that benefits of decision making in electronic media should be characterized not just by ease of acquiring information, but also by the ease in using the information to structure the decision and evaluate alternatives [2]. According to Jarvenpaa \& Todd [9] and Pitkow \& Kehoe [12], one of the difficulties people express in using the Internet is the inability to organize acquired information and to keep track of sources of information. The field of expert sites, though still in its infancy, attempts to alleviate some of the problems mentioned above. The people most likely to use expert sites are those who are comfortable with online transactions but not willing to search for information using traditional search engines. This may be due more to time constraints than the inability to do an effective search.

Sites are changing rapidly, as is evidenced by Xpertsite.com's name change and the purchase of ExpertCentral.com and Abuzz.com. Expert sites are developing partnerships with other sites and raising their advertising rates as more and more people learn about them. Several sites with strong financial backers such as ExpertSite.com, EXP.com and AskMe.com are poised to be successful and will probably be around for a long time. As for the rest, the future remains to be seen.

To the users searching for information and answers via Expert Web Sites, we offer the following advice. Know the site. How does it work? Will it cost anything and, if so, how much are you willing to pay for the information? Do you have to become a member? Know their expertise. Does the site have the expertise you are seeking or are they a specialized site? Know who their experts are. Are they truly experts, volunteers or are they just other people visiting the site? In general, match your question to the site best qualified to give you an answer. Never make important financial or legal decisions based solely on information provided over the Internet and conduct your own crosschecks and research [10].

One should also be aware of who is backing and funding the site. All advice is not necessarily unbiased. The expert site industry is beginning to see some consolidation and interest from advertisers or retailers. This change in direction from "people giving answers to people" to companies giving answers to people can lead to biased advice and sellers taking advantage of potential buyers. For example, companies like EXP.com and AskMe.com now also provide software solutions for businesses to provide expert advice to their customers via the Internet to increase sales and create customer loyalty.

\section{Suggestions For Future Research}

The research presented in this paper opens up several issues that can be studied in future. For example, what are the demographics of the individuals who are most likely to use expert sites? This may be useful in understanding the consumer behavior and trust within knowledge exchange arena. This kind of survey would also be useful to the expert sites as they can better target their promotion strategy. Another potential area of research is developing a metrics for consumer satisfaction when dealing with knowledge exchange - what are the major criteria that can be used in determining the satisfaction from the advice obtained from expert sites. 


\section{References}

1. Abreu, Elinor (2/7/2000), Hints From Heloise Meets the Web, The Industry Standard (On-line). Available: http://www.thestandard.com/article/display/0,1151,9409,00.html

2. Coupey, E., Bodur, O., and Brinberg, D. (1996). "Pre-decision processes in consumer choice," In Advances in Consumer Research, Vol. 25, pp. 226-232. Provo, UT: Association for Consumer Research.

3. Dalton, Gregory (9/6/99). "Rent an Expert on the Web," Information Week, 751, p. 75.

4. eMarketer.com, May 15, 2001

5. Glister, Paul (2/28/2000), Helpful Advice Just a Mouse Click Away, The Raleigh News and Observer, p. D4. Available: http://search.nando.net/plwebcgi/fastweb?getdoc+nao_public_archive+nao_00+8933+0++\%28AskMe\%293AText

6. Guernsey, Lisa (2/3/2000), Everybody's an Expert, New York Times, pp. G-1, G-8.

7. Hamilton, Anita (2/21/2000), Web Know-It-Alls, Time Magazine, V. 155, No. 7, Special Issue Visions, p. 21. Available: http://www.time.com/time/magazine/articles/0,2366,39220,00,html

8. Hearn, Kelly (12/20/99). "Finding Real Experts Online," Christian Science Monitor, 92 (18), p. 16.

9. Jarvenpaa, S.L., \& Todd, P.A. (1997). "Is there a future for retailing on the Internet? In R.A. Peterson (Ed.), Electronic marketing and the consumer (pp. 139-154). Thousand Oaks, CA: Sage.

10. Lyons, Daniel (2/7/2000), Know-It-Alls: Now Up For Bid Online - Help With Your Cat's Ear Infection, Forbes (On-line). Available: http://www.forbes.com/forgesglobal/00/0207/0303042a.htm

11. McDonald, Glenn (Feb 1, 2000). "Experts, Experts, Everywhere", Business 2.0, pp. 208-209 (On-line). Available: http://www.business2.com/magazine/2000/02/20639.htm

12. Pitkow, J.E., \& Kehoe, C.M. (1996). "Emerging Trends in the www user population," Communications of the ACM, Vol. 39, No. 6, pp. 106-108.

13. Poletti, Therese (2/29/2000), Plethora of Web sites offer advice and experts, Reuters (On-line). Available: http://www.online.reuters.com/

14. Vonder Haar, Steven (3/2/2000), Time to Ask The Experts Almost Anything, Inter@ctive Week (On-line). Available: http://www.zdnet.com/intweek/stories/news/0,4164,253905,00.html 
Notes 